\title{
Adult Attention Deficit Hyperactivity Disorder and Its Correlates with the Presence and Severity of Early-onset Alcohol Dependence: An Estimate from a Tertiary Care Center
}

\author{
Shankar Kumar ${ }^{1} \odot$, Sneha Venkatakrishna ${ }^{2}$, Sushmitha Kota ${ }^{3} \oplus$
}

\begin{abstract}
Background: Alcohol dependence is a highly prevalent condition worldwide. Among those with early-onset substance dependence, studies have found that about $30 \%$ have comorbid attention deficit hyperactivity disorder (ADHD). Such patients tend to have severe dependence, poorer outcomes, and failure of classical treatment.

Aim and objective: To study the prevalence of adult ADHD and explore the correlates of ADHD among those with early-onset alcohol dependence. Materials and methods: Eighty-two adult inpatients with early-onset alcohol dependence were recruited for the study after obtaining informed consent. The World Health Organization (WHO) Adult ADHD Screening Rating Scale (ASRS) was used to screen adult ADHD. Wender Utah Rating Scale (WURS) was used to corroborate childhood ADHD symptoms. Severity of Alcohol Dependence Questionnaire (SAD-Q) was administered to determine the severity of dependence. Cohen's Perceived Stress Scale was administered to determine the perceived stress levels in the past 1 month. MINI Plus Neuropsychiatric Interview was administered to rule out mood disorders and antisocial personality disorder (ASPD). Analysis of data was done using $t$-test, Fisher's exact test, Spearman's correlations, and multiple logistic regression analysis to determine the odds of having severe dependence.

Results: Twenty-one out of the 82 subjects with early-onset alcohol dependence had adult ADHD (25.6\%). The severity of alcohol dependence was significantly greater among those with comorbid ADHD $(p<0.001)$. The odds of having ADHD predicting severe dependence was $8(p=0.0004)$.

Conclusion: The prevalence of adult ADHD in those with early-onset alcohol dependence is high. Adult ADHD is a significant predictor of greater severity of alcohol dependence. There is a need for studies that evaluate therapeutic options that would be effective for the treatment of comorbid ADHD and early-onset alcohol dependence.

Keywords: Alcohol dependence, Attention deficit hyperactivity disorder, Severe dependence.

Indian Journal of Private Psychiatry (2021): 10.5005/jp-journals-10067-0075
\end{abstract}

\section{INTRODUCTION}

Attention deficit hyperactivity disorder (ADHD), one of the common childhood neurodevelopmental health disorders with inattention, hyperactivity, and impulsivity, ${ }^{1}$ persists into adolescence and adulthood. ${ }^{2-10}$ The worldwide prevalence of ADHD is about $5 \% .^{11,12}$

A meta-analysis by Reddy et al. revealed that the overall substance use prevalence in India is $6.9 / 1,000 .^{13}$ In clinical settings where substance use disorders (SUDs) are managed, studies have reported that there is a prevalence of up to $30 \%$ of adult ADHD among adolescents and young adults with SUDs. ${ }^{14}$ Patients comorbid with alcohol dependence and ADHD have been found to have severe dependence and an earlier onset of alcohol use. ${ }^{15}$ These patients may also be at a greater risk of failure of classical treatments due to their impulsive and disruptive behavior interfering with treatment compliance. ${ }^{16}$ Adolescents with comorbid ADHD and SUD are also more likely to have negative outcomes ${ }^{17}$ and may be more challenging to treat than adolescents with only one of the diagnoses.

Therefore, detection of ADHD among those with alcohol use aged below 25 years has important implications for prevention and prognosis in the context of alcohol use disorders. In India, there are only a few studies that have explored the variables correlating early-onset alcohol dependence and adult ADHD. Hence, this study was undertaken.

\footnotetext{
${ }^{1-3}$ Department of Psychiatry, Bangalore Medical College and Research Institute, Bengaluru, Karnataka, India

Corresponding Author: Shankar Kumar, Department of Psychiatry, Bangalore Medical College and Research Institute, Bengaluru, Karnataka, India, Phone: +91 9844546083, e-mail: shankarkjs@ gmail.com

How to cite this article: Kumar S, Venkatakrishna S, Kota S. Adult Attention Deficit Hyperactivity Disorder and Its Correlates with the Presence and Severity of Early-onset Alcohol Dependence: An Estimate from a Tertiary Care Center. Ind J Priv Psychiatry 2021;15(1):23-26.

Source of support: Nil

Conflict of interest: None
}

\section{Aim and Objective}

To determine the prevalence and explore the correlates of adult ADHD among those with early-onset alcohol dependence in an inpatient care psychiatric setting.

\section{Materials and Methods}

It was a cross-sectional study undertaken in a tertiary care general hospital psychiatry setting. Seventy-two adult patients with earlyonset alcohol dependence were taken into the study. It was a purposive sampling.

() The Author(s). 2021 Open Access This article is distributed under the terms of the Creative Commons Attribution 4.0 International License (https://creativecommons. org/licenses/by-nc/4.0/), which permits unrestricted use, distribution, and non-commercial reproduction in any medium, provided you give appropriate credit to the original author(s) and the source, provide a link to the Creative Commons license, and indicate if changes were made. The Creative Commons Public Domain Dedication waiver (http://creativecommons.org/publicdomain/zero/1.0/) applies to the data made available in this article, unless otherwise stated. 
Adult Attention Deficit Hyperactivity Disorder and Early-onset Alcohol Dependence

\section{Exclusion Criteria}

Those with psychosis, impulse control disorder, substance use other than alcohol and nicotine, and terminal medical illnesses were excluded from the study as their medical condition could interfere with their ability to complete the questionnaires.

\section{Study Tools}

- Semi-structured questionnaire to collect sociodemographic details.

- The World Health Organization (WHO) Adult ADHD Screening Rating Scale (ASRS): It includes 18 questions about the frequency of DSM IV criterion A symptoms of adult ADHD. It has a sensitivity of $68.7 \%$ and specificity of $99.5 \%$. Out of the initial six questions of ASRS, a cutoff of four was taken as symptoms highly consistent with adult ADHD as suggested by WHO.

Wender Utah Rating Scale (WURS): It is a 61-item retrospective self-report scale used to evaluate adults for ADHD. The adult has to report on their recollection of how they were as a child in the WURS. The WURS has been shown to be a valid retrospective screening and dimensional measure of childhood ADHD symptoms to replicate and correlate with Connors Abbreviated Parent and Teacher Questionnaire and demonstrate internal consistency and reliability and exhibit good construct validity. A cutoff of 44 on WURS was taken for a diagnosis of adult ADHD. ${ }^{18}$

- Severity of Alcohol Dependence Questionnaire (SAD-Q): It is a short, self-administered, 20-item questionnaire designed by the WHO to measure the severity of dependence on alcohol.

- Cohen's Perceived Stress Scale-It is the most widely used psychological instrument for measuring the perception of stress. ${ }^{19}$

- MINI Plus: It is a widely used structured diagnostic interview instrument.

\section{Methods}

Eighty-two consecutive adult patients with early-onset alcohol dependence were recruited for the study after obtaining written informed consent and Institutional Ethical Committee approval.

Sociodemographic data were collected. WHO Adult ADHD Screening Rating Scale (ASRS) was used to screen adult ADHD. WURS ${ }^{18}$ was administered to make a diagnosis of childhood ADHD in retrospect. SAD-Q was administered to determine the severity of dependence. Cohen's Perceived Stress Scale ${ }^{19}$ was administered to determine the perceived stress levels in the past 1 month. MINI Plus was administered to rule out mood disorders and antisocial personality disorder (ASPD) as suggested in Utah criteria.

\section{Statistical Analysis}

Data analysis was done using $t$-test, Fisher's exact test, and Spearman's correlations. Multiple logistic regression analysis was done to find out odds of having severe dependence (31 or higher on the SAD-Q) using adult ADHD, depression, and perceived stress as the predictor variables.

\section{Results}

Out of the 82 subjects with early-onset alcohol dependence, 21 of them had adult ADHD (25.60\%).

We found that those with ADHD had a significantly higher duration of alcohol use, lesser education, and more number of jobs held that are illustrated in Table 1, and Table 2 illustrates that those with ADHD significantly had higher severity of alcohol dependence.

We found that there were no statistically significant differences in the presence of depression or ASPD between those with and without ADHD as in Table 3. There were an eight-fold odds of having adult ADHD and four-fold odds of having depression in those with severe dependence. However, in view of the wide confidence interval $(\mathrm{Cl})$, this finding should be interpreted with caution (Table 4).

\section{Discussion}

This study was undertaken to determine the prevalence and explore the correlates of adult ADHD among those with early-onset alcohol dependence in an inpatient care psychiatric setting.

Out of the 82 subjects with early-onset alcohol dependence, 21 of them had adult ADHD (25.6\%). This is higher than the prevalence of adult ADHD in the general population. ${ }^{20}$ This is similar to the findings of other studies where the prevalence of adult ADHD was found to be more in those with SUDs. ${ }^{21}$

Those with ADHD had significantly greater years of alcohol use, lower years of education, a greater number of changes in jobs, and younger age at marriage than those without ADHD (Table 1). This is in concordance with previous studies that have found that people with ADHD generally have lower educational attainments $s^{8,11,14}$ due to impulsivity and inattention ${ }^{10}$ and resultant poor self-confidence and social dysfunction., 94

Hyperactivity, impulsivity, and overall symptom severity of ADHD in childhood were associated with high dropout rates in school, whereas persistent inattention and other comorbid mental disorders correlated to occupational impairment. ${ }^{14}$ Studies have also shown that ADHD subjects with alcohol dependence have poor job records ${ }^{11,14}$ and marital adjustment in view of maladjustment as a result of ADHD symptoms. ${ }^{14}$

Those with ADHD had significantly higher severity of alcohol dependence than those without ADHD (Table 2). Also, those with ADHD had a greater duration of alcohol use and thus earlier age at onset, which is in concordance with the existent literature. In a previous study done by Arias et al., ADHD was associated with an earlier age of first substance use and more substance dependence. ${ }^{22}$ Studies also suggest that individuals with ADHD have a shorter interval between the onset of drug abuse and drug dependence. Substance abuse is transitioned more rapidly to dependence and lasts longer in adults with ADHD than those without ADHD. ${ }^{23}$ This may further pave way to other drugs as described by the gateway drug hypothesis that refers to the pattern of substance use during adolescence whereby legal substances, such as nicotine and alcohol, precede the progressive use of illicit substances like cocaine and heroin. ${ }^{24}$

Multiple logistic regression analysis was used to determine the factors associated with severe dependence (as scored by SAD-Q) (Table 4). The odds of having severe dependence in those with comorbid ADHD were eight in our study, which is in concordance with the existing literature that says those with adult ADHD had more severe substance dependence. ${ }^{22}$ The odds of severe dependence in those with comorbid depression (as per DSM IV criteria) were four. This is again in line with the previous study that has found that the prevalence of depression among alcohol-dependent persons is high (63.8\%) with a significant association between depression and the mean AUDIT score. ${ }^{25}$ Both of these predictors were found to be statistically significant in predicting the severity of dependence. 
Adult Attention Deficit Hyperactivity Disorder and Early-onset Alcohol Dependence

Table 1: Sociodemographic profile-differences between those with and without ADHD

\begin{tabular}{lcccccccc}
\hline & \multicolumn{2}{c}{$A D H D(n=21)$} & & \multicolumn{2}{c}{ No $A D H D(n=61)$} & & \\
\cline { 2 - 3 } & Mean & $S D$ & & Mean & $S D$ & & p-value & $t$-value \\
\hline Years of alcohol use & 10.51 & 4.61 & & 7.31 & 3.93 & $0.008^{\mathrm{a}}$ & 2.73 \\
Years of education & 6.52 & 4.83 & & 11.54 & 3.49 & $0.0001^{\mathrm{a}}$ & 4.63 \\
Income (rupees) & 14,500 & 6,850 & & 16,750 & 5,610 & 0.18 & 1.32 \\
Age at marriage (years) & 22.42 & 8.23 & & 24.21 & 6.44 & 0.29 & 1.09 \\
Years of marriage & 6.86 & 2.43 & & 5.45 & 3.17 & $0.03^{\mathrm{a}}$ & 2.09 \\
Number of jobs held & 3.24 & 0.89 & & 2.86 & 0.67 & $0.02^{\mathrm{a}}$ & 2.14 \\
\hline
\end{tabular}

aepresents $p \leq 0.05$ as significant

Table 2: Differences in perceived stress and severity of alcohol dependence between those with and without ADHD

\begin{tabular}{lcccccc}
\hline & NDHD & ADHD & $t$-value & $d f$ & $p$-value & F-value \\
\hline $\begin{array}{l}\text { SAD-Q } \\
\text { score }\end{array}$ & 34.87 & 23.37 & 5.24 & 82 & $<0.001^{\mathrm{a}}$ & 2.98 \\
$\begin{array}{l}\text { Perceived } \\
\text { stress }\end{array}$ & 14.59 & 12.69 & 1.08 & 82 & 0.27 & 1.45 \\
\hline
\end{tabular}

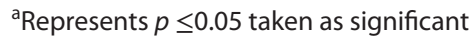

Table 3: Depression and ASPD in those with and without ADHD

\begin{tabular}{lccc}
\hline Fisher's exact test & ADHD & No ADHD & -value \\
\hline Depression & 6 & 12 & 0.18 \\
ASPD & 3 & 07 & 0.42 \\
\hline
\end{tabular}

Table 4: Multiple logistic regression to predict the odds of having severe dependence using ADHD, perceived stress, and depression as the predictor variables

\begin{tabular}{lccccc}
\hline & \multicolumn{3}{c}{$\begin{array}{c}\text { Standard } \\
\text { error }\end{array}$} & $p$ & $\begin{array}{c}\text { Odds } \\
\text { ratio }\end{array}$ \\
& $R 2$ & $95 \% \mathrm{Cl}$ \\
\hline Adult ADHD & 2.70 & 0.77 & $0.0004^{\mathrm{a}}$ & 8.78 & $3.28-33.38$ \\
$\begin{array}{l}\text { Perceived } \\
\text { stress }\end{array}$ & 0.02 & 0.04 & 0.54 & 1.03 & $0.94-1.15$ \\
Depression & 1.38 & 10.64 & $0.03^{\mathrm{a}}$ & 4.04 & $1.11-14.72$ \\
\hline
\end{tabular}

Represents significant association; Overall model fit-chi $s q=22.9, \mathrm{df}=3$, $p=0.003^{\mathrm{a}}$; Severe dependence $(n=28)$ and mild-moderate dependence $(n=54)$

Though we assumed that the odds of having severe dependence were due to the high comorbidity of ADHD with depression and ASPD, we did not find a significant difference in these parameters among those with and without ADHD. Thus, factors related to adult ADHD, like executive impairments that include impaired behavioral inhibition, regulation of emotion, and motivation, as postulated by Barkley could probably account for severe dependence in these individuals. $^{26}$

In a study done by Daurio et al., it was found that overall adult ADHD symptoms, and more specifically, symptoms of hyperactivity or restlessness and problems with self-concept, increased the odds of having a diagnosis of alcohol dependence. Within the alcohol dependence patients, it was found that impulsivity mediated the relationship between adult ADHD symptoms and alcohol dependence severity. ${ }^{27}$
All these evidences reemphasize the need for thorough screening of ADHD, early diagnosis, and management in order to prevent substance dependence, if possible, or at least alter its prognosis in this vulnerable group.

\section{Limitations}

This study has a number of limitations. The Sample size is small and cross-sectional study design makes it unable to study the prognosis and effectiveness of treatment options. Other associated factors with early-onset alcohol dependence, such as conduct disorder, childhood bipolarity, personality traits such as impulsivity and affective instability, were not evaluated. The severity of adult ADHD was not assessed as ASRS is a screening instrument and does not measure severity. The sample, in general, had higher severity of dependence as reflected by SAD-Q scores as this is a sample from a referral center and hence not representative of a community sample. Nevertheless, in this study, all patients were evaluated with structured diagnostic interviews by trained clinicians, and evaluations were not based on self-reported questionnaires or retrospective data only.

\section{Conclusion}

Prevalence of adult ADHD was high in those with early-onset alcohol dependence. Adult ADHD along with depression was a significant predictor of greater severity of alcohol dependence. Studies need to evaluate therapeutic options that would be effective for the treatment of comorbid ADHD and early-onset alcohol dependence.

\section{OrCID}

Shankar Kumar $\odot$ https://orcid.org/0000-0002-8002-4576 Sneha Venkatakrishna @ https://orcid.org/0000-0002-4575-9446

Sushmitha Kota @ https://orcid.org/0000-0003-0668-4944

\section{References}

1. Kooij SJ, Bejerot S, Blackwell A, et al. European consensus statement on diagnosis and treatment of adult ADHD: the European Network Adult ADHD. BMC Psychiatry 2010;10:67. DOI: 10.1186/1471-244X-10-67.

2. Barkley RA, Fischer M, Smallish $L$, et al. The persistence of attentiondeficit/hyperactivity disorder into young adulthood as a function of reporting source and definition of disorder. J Abnorm Psychol 2002;111(2):279-289. DOI: 10.1037/0021-843X.111.2.279.

3. Biederman J, Petty CR, Clarke A, et al. Predictors of persistent ADHD: an 11-year follow-up study. J Psychiatr Res 2011;45(2):150-155. DOI: 10.1016/j.jpsychires.2010.06.009.

4. Biederman J, Petty CR, O'Connor KB, et al. Predictors of persistence in girls with attention deficit hyperactivity disorder: results from 
an 11-year controlled follow-up study. Acta Psychiatr Scand 2012;125(2):147-156. DOI: 10.1111/j.1600-0447.2011.01797.x.

5. Fayyad J, De Graaf R, Kessler R, et al. Cross-national prevalence and correlates of adult attention-deficit hyperactivity disorder. $\mathrm{Br} J$ Psychiatry 2007;190:402-409. DOI: 10.1192/bjp.bp.106.034389.

6. Kessler RC, Adler LA, Barkley R, et al. Patterns and predictors of attention-deficit/hyperactivity disorder persistence into adulthood: results from the national comorbidity survey replication. Biol Psychiatry 2005;57(11):1442-1451. DOI: 10.1016/j. biopsych.2005.04.001.

7. Kessler RC, Adler L, Barkley R, et al. The prevalence and correlates of adult ADHD in the United States: results from the National Comorbidity Survey Replication. Am J Psychiatry 2006;163(4): 716-723. DOI: 10.1176/appi.ajp.163.4.716.

8. Lara C, Fayyad J, De Graaf R, et al. Childhood predictors of adult attention-deficit/hyperactivity disorder: results from the World Health Organization World Mental Health Survey Initiative. Biol Psychiatry 2009;65(1):46-54. DOI: 10.1016/j.biopsych.2008.10.005.

9. Mannuzza S, Klein RG, Moulton JL III. Persistence of attention- deficit/ hyperactivity disorder into adulthood: what have we learned from the prospective follow-up studies? J Atten Disord 2003;7(2):93-100. DOI: $10.1177 / 108705470300700203$.

10. Sandra Kooij JJ, Buitelaar JK, van den Oord EJ, et al. Internal and external validity of attention- deficit hyperactivity disorder in a population-based sample of adults. Psychol Med 2005;35(6):817-827. DOI: 10.1017/s003329170400337x.

11. Polanczyk GV, Salum GA, Sugaya LS, et al. Annual research review: a meta-analysis of the worldwide prevalence of mental disorders in children and adolescents. J Child Psychol Psychiatry 2015;56(3): 345-365. DOI: 10.1111/jcpp.12381.

12. Biederman J, Wilens TE, Mick E, et al. Does attention-deficit hyperactivity disorder impact the developmental course of drug and alcohol abuse and dependence? Biol Psychiatry 1998;44(4):269-273. DOI: 10.1016/s0006-3223(97)00406-x.

13. Barkley RA, Fischer M, Smallish L, et al. Young adult follow-up of hyperactive children: antisocial activities and drug use. J Child Psychol Psychiatry 2004;45(2):195-121. DOI: 10.1111/j.14697610.2004.00214.x.

14. Fredriksen M, Dahl AA, Martinsen EW, et al. Childhood and persistent ADHD symptoms associated with educational failure and long-term occupational disability in adult ADHD. Atten Defic Hyperact Disord 2014;6(2):87-99. DOI: 10.1007/s12402-014-0126-1.
15. Sullivan MA, Rudnik-Levin F. Attention deficit/hyperactivity disorder and substance abuse. Diagnostic and therapeutic considerations. Ann N Y Acad Sci 2001;931:251-270. DOI: 10.1111/j.1749-6632.2001. tb05783.x.

16. Wilens TE. The nature of the relationship between attentiondeficit/hyperactivity disorder and substance use. J Clin Psychiatry 2007;68(Suppl. 11):4-8. PMID: 18307375.

17. Wise BK, Cuffe SP, Fischer T. Dual diagnosis and successful participation of adolescents in substance abuse treatment. J Subst Abuse Treat 2001;21(3):161-165. DOI: 10.1016/s0740-5472(01)00193-3.

18. Ward MF, Wender PH, Reimherr FW. The Wender Utah Rating Scale: an aid in the retrospective diagnosis of childhood attention deficit hyperactivity disorder. Am J Psychiatry 1993;150(6):885-890. DOI: 10.1176/ajp.150.6.885.

19. Cohen S, Kamarck T, Mermelstein R. A global measure of perceived stress. J Health Soc Behav 1983;24(4):385-396. Available from: https:// doi.org/10.2307/2136404

20. Faraone SV, Biederman J. What is the prevalence of adult ADHD? Results of a population screen of 966 adults. J Atten Disord 2005;9(2):384-391. DOI: 10.1177/1087054705281478.

21. Van de Glind G, van Oortmerssen KV, Carpentier PJ, et al. The international ADHD in substance use disorders prevalence (IASP) study: background, methods and study population. Int J Methods Psychiatr Res 2013;22(3):232-244. DOI: 10.1002/mpr.1397.

22. Arias AJ, Gelernter J, Chan G, et al. Correlates of co-occurring ADHD in drug-dependent subjects: prevalence and features of substance dependence and psychiatric disorders. Addict Behav 2008;33(9): 1199-1207. DOI: 10.1016/j.addbeh.2008.05.003.

23. Wilens TE. Impact of ADHD and its treatment on substance abuse in adults. J Clin Psychiatry 2004;65(3):38-45. PMID: 15046534.

24. Miller M, Hurd Y. Testing the gateway hypothesis. Neuropsychopharmacol 2017;42:985-986. DOI: 10.1038/npp.2016.279.

25. Kuria MW, Ndetei DM, Obot IS, et al. The association between alcohol dependence and depression before and after treatment for alcohol dependence. ISRN Psychiatry 2012;482802:6 p. DOI: 10.5402/2012/482802

26. Barkley RA, Murphy KR. Attention deficit hyperactivity disorder: a clinical workbook. New York: Guilford; 2006.

27. Daurio AM, Aston SA, Schwandt ML, et al. Impulsive personality traits mediate the relationship between adult attention-deficit/ hyperactivity symptoms and alcohol dependence severity. Alcoholism 2018;42(1):173-183. DOI: 10.1111/acer.13538. 